\title{
Criminological and investigative analysis of sexual vicious behaviour
}

\author{
Marcello Savastano, ${ }^{1}$ Monica Calderaro, ${ }^{2}$ Giulia Maestoso ${ }^{3}$ \\ ${ }^{1}$ Capitan of Army of Carabinieri; ${ }^{2}$ Criminologist, graphologist, headmaster and professor of the Graphology course of \\ Sapienza University of Rome. Professor of Psychographology and Crime in social media of the Master of Criminology in \\ the University of International studies of Rome (UNINT). Researcher of the International Institute of Criminological and \\ Psychopathological forensic science (IISCPF); ${ }^{3}$ Degree in Clinical and Community Psychology; Master in "Criminology, \\ penal system, forensic psychopathology, investigation and security" directed by Prof. Mastronardi at the International uni- \\ versity (UNINT), Italy
}

\begin{abstract}
The following work is going to treat assembling main studies about the topic, the criminological analysis of sexual vicious behavior, outcome of a research led within a Master's contest about "Criminology, investigative and strategic sciences for security", by the Unitelma Sapienza University of Rome. The number of victims caused by this peculiar aberration of human behavior, per year, is comparable to a war: even though, of the latter one, shares only a subtle gradient of aggressiveness, produced or linked with sexual choices and not relating to more socially-elaborated frames, growth out to a political-military basis. Therefore, "Behavior", first and foremost, "sexual vicious", furthermore: this one is the indivisible hendiadys that will remark the "behavior" on which the focus points into, to no scatter speculative energies and to tighten the essay's core in two clamped angles of research, that otherwise could spread outwards, becoming loose and approximative. Consequently, will be of preliminary importance to start from the semantic compounds between aggressiveness and sex, that spread themselves in the definitions of rape and sexual abuse. Possibly, we will obtain a perimeter, a slot from which observe the general topic about the sexual normality and deviance: in the twilight interstice, stemmed from the difference between these two poles, that could seem a prism but also an opaque and shady tissue, the sexual vicious behavior shows off its dynamics, its inner mechanics, its selfpropelling criminal engine. Of course, the article's structure had to contemplate all the psychodynamic path of the sex offender, profiting by methodological guidelines of prof. Vincenzo Mastronardi, so arriving in a ranking whose value, probably, founds the peak utility in investigative environments (if there was an acting-out).
\end{abstract}

\section{RIASSUNTO}

Il lavoro che segue tratterà, rassegnando le principali ricerche in materia, l'analisi criminologica del comportamento sessuale violento, frutto di una ricerca condotta nell'ambito del Master in "Criminologia, scienze investigative e strategiche per la sicurezza" dell'Università Unitelma Sapienza di Roma. I numeri delle vittime di questa peculiare aberrazione del comportamento umano, per anno, sono paragonabili a quelli di una guerra: eppure, di quest'ultima, ne condividono solamente un certo gradiente di violenza, generata o correlata a opzioni di natura sessuale e non in contesti socialmente più elaborati di matrice politico-militare. Per cui "comportamento", innanzitutto, "sessuale violento", poi: quest'ultima è l'endiadi inscindibile che connoterà il "comportamento" su cui punta il focus, per non disperdere le energie speculative e per stringere in due serrati angoli di ricerca l'argomento, che altrimenti presterebbe il fianco ad infinite indagini euristiche, ovvero a gradazioni prospettiche troppo ampie e, quindi, inesorabilmente approssimative. Risulterà pertanto di preliminare rilevanza partire dalle combinazioni semantiche tra violenza e sesso, che si irradiano nelle definizioni di stupro ed abuso sessuale. Si otterrà, auspicabilmente, un perimetro, una feritoia dalla quale osservare l'argomento più generale attinente la normalità e la devianza sessuale: nell'interstizio chiaroscurale, ricavato dalla breve ed incerta distanza tra questi poli, che può essere sì un prisma ma anche uno stagnante tessuto opaco ed adombrante, il comportamento sessuale violento svela la propria meccanica, il proprio intrinseco funzionamento, la propria semovenza criminale. Certamente, la strutturazione dell'articolo doveva tenere in considerazione tutto l'itinerario psicodinamico del sex offender, traendo particolare giovamento dalle indicazioni metodologiche del prof. Vincenzo Mastronardi, così arrivandone, in ragione delle singole estrinsecazioni della devianza, ad una classificazione il cui valore, probabilmente, trova l'apice della propria utilità in ambienti investigativi (laddove vi sia stato un acting-out).

\section{RESUMEN}

El trabajo que sigue, al renunciar a la investigación principal sobre este tema, el análisis criminológico del comportamiento sexual violento, es el resultado de una investigación realizada en el Máster en "Criminología, Ciencias de Investigación y Estratégicas para la Seguridad" en la Universidad Unitelma Sapienza Roma. El número de víctimas de esta peculiar aberración del comportamiento humano por año es comparable al de una guerra, sin embargo, estas últimas solo comparten un cierto grado de violencia, generada o relacionada con opciones de naturaleza sexual, y no contextos socialmente más elaborados de la matriz político-militar. Por lo tanto, "comportamiento" es en primer lugar un "sexo violento", entonces: este último es la dotación inseparable que transmitirá el "comportamiento" en el que se enfoca el foco, para no dispersar las energías especulativas y sujetar en dos esquinas de la búsqueda el argumento, que de otra manera se adheriría a investigaciones heurísticas interminables, o a grados prospectivamente amplios y por lo tanto inexorablemente aproximados. Por lo tanto, será de primordial importancia a partir de las combinaciones semánticas entre violencia y sexo, que irradian las definiciones de violación y abuso sexual. Esperemos hallar un perímetro, una rendija

The term "human" could be added, but it would seem like a definite pleonasm, if it were not that the instinctively of sexual impulse, unconnected with the most sophisticated rules of Eros and desire, can make the criminal acting-out at a more animal-like level. 
desde la cual observar el argumento más general sobre la normalidad y la desviación sexual: en el intersticio de claroscuro, obtenido a partir de la distancia corta e incierta entre estos polos, que puede ser un prisma, pero también uno Tejido mate y opaco estancado, el comportamiento sexual violento revela su propia mecánica, su funcionamiento intrínseco, su propia auto evolución criminal. Ciertamente, la estructuración del artículo debe tener en cuenta todo el itinerario psicodinámico del delincuente sexual, obteniendo un beneficio particular de las indicaciones metodológicas del prof. Vincenzo Mastronardi, llegando, en razón de la extinción individual de la desviación, a una clasificación cuyo valor probablemente encuentre su aptitud en los entornos de investigación (donde ha sido un acting-out).

\section{Rape and sexual abuse: in search of a legal and criminological definition}

Describing the psychodynamics of sexual violence imposes immediately, a methodological premise on the very definition of "violence", then to understand when and in what way such "violence" becomes "sexual" and yet, if "violent sexuality" is understood criminologically, even perpetrated through long-lasting behavioral modules, always has an adequate legal remuneration. The problem of deviance, as we know, is overcome by the strict legal qualification of a fact as a "crime", dealing with criminology and social reaction to it (Ponti, 1999, p. 6). Therefore, one can not expect to settle for a jurisprudential review of "sexual violence" (although copious and collateral to the problem of sexual deviance tout court), but it is necessary to know from the legal fabric that the underlying criminological mantra is extracted, making it as detachable as possible from a cultural and social system that has contributed to a regulatory reconnaissance, so that it is possible to overcome the problems, namely, psychodynamic and exquisitely investigative (and hence the criminal procedure) ${ }^{2}$.

It is evident that the complexity of the subject feeds on the difficult recognition of the sociological and anthropological function (which is largely the legal definition of a legal right) of "sexuality", the conceptualization of which differentiates, on one hand, the " sexual acts "(masturbation, kiss or penetration) and, on the other hand, the " sexual behaviors "(courtship, choice of clothing, watching a movie ...) with their respective "reproductive" (procreation of offspring), "recreational" (pleasure or play) or "relational" (communicative exchange with the person) finalizations. The combination of these elements, besides creating a remarkable heuristic phenomenology, is then articulated on the typically connotative meanings of sexual experience related to the emotional responses that they generate in the individual (Dector, 2001, p. 2).

Italian legislation, symmetrical in the contents and in the social disagreement of the main conducts censored to other Western norms, to our ends, is an indispensable starting point if we want to frame the subject with a cold and rational approach, i.e. devoid of the emotional impulses mentioned previously ${ }^{3}$ : we will therefore begin with the criminal analysis of art. 609 bis of the Italian Penal Code to draw from the legal fabric the necessary points for the criminological and psychodynamic description of violent sexual behavior.

Article. $609^{4}$ bis p.c. punishes: "Anyone who, by violence or threat or by abuse of authority, forces someone to commit or suffer sexual acts, is punished with imprisonment for five to ten years. The same punishment is given to those who induce someone to commit or suffer sexual acts:

1) abusing the physical or psychological inferiority of the offender at the time of the offense;

2) by deceiving the injured person to be the offender replaced by another person.

In cases of lesser severity, the penalty is reduced to an extent not exceeding two-thirds".

This is a recently introduced rule or, rather, a recent reformula- tion, having entered the offense against the person only with the law of 15 February 1996, n. 66, where the pin was the very concept of "sexual act" that unites, bonding positive protection, acts of libido and carnal violence. The new wording, in the intentions of the legislator, should have made the victim's story less painful for the victim, since the court has no longer to decide based on this story the applicable law in relation to the quality of the act. Innovation also underpins a renewed conception of sexuality understood in its psychosomatic complexity, unconnected with assessments depending on the area of the body drawn (Ciafardini et al., 2009, p. 1287). This is a breakthrough between the legal definition and the criminological appreciation of sexual violence / sexual abuse / rape: the sexuated body acts, in its entirety bio-psychological, as an active and sometimes resistant factor in both subordinate and subjugation (Bourke, 2011, p. 11). Which means that it is useful to know, in the construction of the legal punitive model and in the understanding of criminodynamics, consensus and coercion, that are the fulcrums on which all the major rape definitions are rotated. It is also to be noted that the Italian positive-penalty definition, like other Western contemporary laws, does not provide for penile penetration as a constituent element of the legal case, which, far from being of secondary importance, especially in feminist or phallocentric perspective, constitutes an interesting weighting about the configurability of the offense by anyone, regardless of their anatomical or gender type. On this subject, a taxonomy (as exhaustive as possible) of the sex offender will be listed, in whose river, it will be necessary to dwell on the feminine and male criminodynamic characteristics.

However, from the investigative point of view, a distinction must be made between the sexual act with the penetration of the aggressor's genital organ into the victim's genital organ, or rather the manipulation of the victim's body with concomitant sexual excitement ${ }^{5}$. Violence does not necessarily have to overcome any possible resistance of the victim by limiting and abolishing its ability to choose (Ferracuti, 1988, p. 317), as is the case where dissent can not be expressed because of the speed of the victim aggressor, or because of the immobilization resulting from the shock of the victim.

2 The author identifies three main factors to explain the complexity of the approach to the sexual subject: 1) the possibility of procreating new human beings, both in the positive sense (the pleasure of having a child) and negative (the load of responsibilities and burdens involving the creation of new individuals on an individual and social level); 2) the physiological pleasure associated with the wide type of sexual acts and the high intrinsic reinforcement value, so that they tend to be repeated more than the other acts; 3 ) intimacy (physical, but generally also psychological) that sexual behaviors and acts require; this is obviously necessary in torque dynamics, but it is also in the case of a solitary act like masturbation.

3 And other diversified components that affect the view of the individual sex: it will be discussed below about the ontogenesis of sexual behavior.

4 Literary translation from Italian to English.

Behaviors to which possible paraphilic disorders correspond (which will be discussed in detail below). 
For the purposes of our analysis, it will be necessary to evaluate the overcoming of the threshold of violence, albeit moderate, to obtain an appropriate and universal benchmark. The risk is getting lost in the extreme flourishing of erotic phenomenologies, related to sexuality, which changes in relation to the time and place axis, relativizing the abnormal / normal sex ${ }^{6}$, to the point of weakening the gradient of deviance, changing in relation to time and place of formulation.

On this basis, it seems effective to indicate as "rape" all those sexual abuses perpetrated with or by means of violence, threat or astute persuasion, regardless of the relationship between aggressor and victim: in this way, rape is included in marriage and in all those situations in which someone, as an aid bidder, has sexual contact with the person in need of help (i.e. teacher / student, lawyer / client, doctor / patient). In all these cases in which the attacker is known to the victim, the consequences are however traumatic both for the psychological and physical damage caused, and are similar to those committed by strangers, even though they are characterized by a significant degree of physical violence (Palermo, Mastronardi, 2008, p. 199). Even other definitions seem effective ${ }^{7}$, but probably do not allow the criminological overview that deals with it.

\section{Ontogenesis of violent sexual behavior}

It is necessary to consider sexual behavior - in general - as the result of an interaction, extremely variable in its course and its results, between a limited innate base and complex learning factors. The modalities of learning the various behaviors of a sexual nature are further complicated by the fact that they, besides the fundamental reproduction (so-called phylogenetic), can perform many other functions and therefore maintain themselves based on numerous reinforcing components, among which are been identified (Dèttore, 2001, p. 56): the affirmation of one's own masculinity or femininity; strengthening or maintaining one's self-esteem; exercise of power or domination; creation of dyadic relationships and a relationship of intimacy; source of pleasure; voltage reduction (anxiolytic effect); expression of hostility; excitement as a result of running risks; advantages and material gains. Hence, the heterogenesis of sexual ends modulates the material consummation of sexual acts and behaviors, characterized according to the qualitative and quantitative connotations of the author and the relational whole of the protagonists. Of our interest, it should be noted that among the typical qualitative characteristics of human sexuality undoubtedly stands out eroticism ${ }^{8}$ : what differentiates the simple sexual activity from eroticism (from Eros = "passionate desire") is a psychological research independent of the natural end of procreative sexuality. It is an aspect of the inner life of man that seeks an object of desire placed outside. This object corresponds to the interiority of desire. To note: the sexual activity of man is not necessarily erotic; it is only to the extent that it is not raw or simply animal (Quattrini, 2015, p. 241) 9

There is a structural correlation between sexual behavior and the modules of learning accepted more or less consciously by the individual, intuitively imbued with cultural, social, and biological specificities... It seems to justify the inference that no form of sexual activity is intrinsically and aprioristically normal or abnormal if we do not consider the frame in which it occurs and the purposes for which it is declined.

And this seems even more syllogistically founded considering that some sexual behaviors, even if departing from normativity, do not forcefully enter into the panorama of the paraphilias, nor in those of crime and sexual violence ${ }^{10}$, further allowing the exact identification of the boundary line separating them from the abnormal: there is a dimension that has to do simply with the personal emotion and energy of erotic-sexual pleasure, and which has its roots in curiosity, making the conceptual and lexical coordinates more childish, in the enjoyment, where the particular social context of transgression is placed.

Sexual transgression exists in all people (Quattrini, 2015, p. 28 ) and is the expression not only of the erotic novelty, but also of the experimentation of the "real" and implicit needs of each individual. Therefore, everything that appears singular and different in the imaginary of the human being is transgressive (in its social dimension, since it is precisely the overthrow of the sexual taboo to label behavior from normative to transgressive).

Once the boundary of transgression has been overcome, the paraphilic experience fully enters, which, despite the intense and persistent excitation of the subject to reiterate the "particular" erotic behavior, does not require therapeutic intervention. When the paraphiliac behavior shows a particular state of distress and the individual manifests consequences of discomfort from the social, work and emotional-relational point of view, then we can speak of Paraphilic Disorder, whose classification is of a clinical nature. The overcoming of this taxonomic threshold, opens the limbo to those who use this behavior with the sole purpose of harming another person other than himself (feeding the sexuality of this unique teleology of pain), without particular excitement or sexual erotic pleasure: these subjects call themselves sex-offenders. Individuals who do not resort to violence for sexual erotic purposes, but to destroy the other, invading the victim of hatred, resentment and punishment, often suffered personally or otherwise experienced previously and never reworked ${ }^{11}$.

Considering the above, it appears particularly effective - especially for the didascalic value and for the synthesis framework definitively composed by the authors (Dettore, 2001, p. 133) - to retrace the essential schematism of the cognitive-behavioral model of sexuality, that is a model analysis of sexuality and emotional

6 The topic will be discussed later on the ontogenesis of violent sexual behavior.

7 For example, the US Federal Bureau of Investigation (FBI) provides a more concise definition: "[...] is the carnal knowledge of another person, imposed by force and against his/her will [...]" (Uniform Crime Report, 1992, p. 76). In his Theories of Rape (1989) Lee Ellis defines rape "an attack on sexual intimacy that is imposed by physical force when one of the subjects involved decides not to have intimate sexual relations", adding that such terms as "forced sex" or "sexual assault", which are already in use in several American jurisdictions, may be more appropriate than "rape".

8 A concept that goes beyond the content of pornography, due to its contents and psychodynamic structure, which will be discussed below

9 The setting is by Bataille (1957), which continues: "[...] Eroticism, basing its roots in the emotional experience of sexual desire, detaches itself from the sexual act as an end in itself and is expressed in forms and activities not directly connected to its concrete fulfillment: it uses phantasy and imagination. "(cit., ibi., p. 242)

10 The so-called continuum normative-transgressive / paraphilia / Paraphilic-sex offender Disorder (Quattrini, 2015, p. 26).

11 The differentiation of levels, as claimed by the author and whose corollary is shared, allows a first important step towards the culture of differences. Staying attached to the collective and social normativeness promotes dangerous forms of anger, constantly reinforcing the concept of deviance: this is not necessarily understood as a sociological expression of a deviation from "normality", but as a psychic fixation and narcissistic conviction of a thought that rigidly develops violent, discriminators and often humiliating and poorly behaving, such as bullying or homo / transphobia. 
behavior linked to it. According to this approach, the behavior of a subject is considered as the response to a stimulus that can be internal (cognitive, that is, ideational, or proprioceptive, which derives from the self-perception of their own physiological processes), external or behavioral (coming from the environment and / or from one's own or from the other's behavior).

This type of response consists of three components: the cognitive one, linked to the electrocortical activation (i.e. the cerebral cortex); the emotional one, deriving from the activation of the limbic and the neurovegetative system (orthosympathetic and parasympathetic); and the behavioral one, following the motor activation of the skeletal muscles. It depends, in its quality and quantity, on the interaction of these three components which, in turn, are triggered and regulated by constitutional mechanisms (the innate biological endowment) and by learned processes (expectations, based on self-identity and on belief systems and values systems); the whole is inserted in complex feedback circuits so that every element of the chain is modified by the functioning of the others and, at the same time, modifies it ${ }^{12}$.

Absolutely relevant in this setting is that of "arousal" or "physiological activation": the process by which the body is activated to deal with the problematic circumstances of existence. This response of exaltation of the level of functioning is adaptive because it puts the subject in the best conditions to react to a potential danger, through the electrocortical activation (which favors the activity of brain neurons), the neurovegetative activation (which produces a sequence of biochemical changes that enhance muscle response) and motor activation (which increases the tone of the muscles, increasing their power and the speed of contraction). All these changes are perceived by the subject and, generally, are experienced as anxiety or in the form of other emotions according to the various biological modules in which they are expressed and according to the cognitive interpretations that each of them gives based on the circumstances, expectations and personal baggage of experiences. Furthermore, it is essential that the optimal activation level for an effective response is medium, neither too low nor too high, otherwise there is inertia or disorganization of behavior (see Law of Yerkes-Dodson, 1908).

The development of sexuality and appropriate emotional behavior is the integration of complex skills in the following four areas:

a) biological field, consisting of the innate biological endowment, that is chromosomal sex and neuroendocrine system;

b) emotional field, consisting of the trait emotional responses ${ }^{13}$ (predominantly innate component) and emotional responses learned;

c) cognitive field, in the dual aspect of conscious conceptual activity and unconscious processing operations. In the sexual field ${ }^{14}$, we have knowledge about the physiology of the reproductive system, conception, pregnancy, contraception, sexual habits and customs, as well as some specific cognitive abilities ${ }^{15}$;

d) motor (or behavioral) field, formed by innate and learned motor repertoires, which constitute the majority. In the sexual field it is necessary to point out that, beyond the apparent spontaneity that seems to characterize behavior, important skills contribute to determining its proper conduct. Among the most relevant, the social ones (and therefore capture and convey the "form" of social communication) and self-regulation, or anxiety management.

\section{Other consideration on sexuality: irrational fears, pornography and correlations with rape}

The ancestral interweaving between innate sexuality and culturally variable learning modules (and, as mentioned, preponderant in the approach to the erotic experience) is not immune to irrational fears (phobias) which, arising from ethical, religious or even related to popular / family traditions, subtended by individual consciousness, burst into the dynamic love or relational / erotic, modifying and forging its development and, at times, inhibiting its natural course. In this regard, it should be noted that these sexual dysfunctions are the direct result of erroneous or unrealistic expectations and beliefs that generate anxiety with respect to various aspects of sexual intercourse. The natural corollary is that even the psychodynamics of violent sexuality develops from these particular phobias which, by definition, are "irrational" and, therefore, difficult to assimilate cognitively for the subject (offender), especially in the context of more or less serious psychopathological frameworks, can lead to the extrinsication of particularly violent acting-out, or deviant behavior. In this sense, in investigating the psychological profile of the rapist, Jung notes that rape is the act of someone who can not symbolize his deep impulses; the rapist seems to have little capacity for reflection. He is possessed by uncontrollable intrapsychic forces that maneuver his will and inexorably drag him towards unconscious gestures.

Among the most common phobias, we report (Dèttore, 2001, p. 97):

a) the fear of sexual enjoyment: usually linked to a conception of sexuality as guilt or sin, or considered as something dirty or impure;

b) the fear of not succeeding (performance anxiety): it is the result of rigidity in expectations regarding sexual intercourse and compulsory commitment to the partner, but above all the attribution of values and aims to sexual intercourse incompatible with a vision of it as pleasure and satisfaction, becoming a challenge rather than a virility test;

c) the fear of losing control: often present in anorgasmic women, is the result of the unrealistic conviction of having to maintain dominion over oneself and the fear of being able to behave in an unseemly way in case of complete abandonment to pleasure;

d) the fear of the other sex: usually it is the consequence of ignorance (due to inexperience, wrong education, social circumstances of deprivation or unfavorable circumstances) in relation to the relationships that can be obtained from the represen-

12 According to this perspective, starting from an innate organic base, the weight of the learning processes is fundamental for the emission of the behavioral response.

13 Regarding personality traits we refer to the Eysenck theory which bases its personological distinctions on physiologically, experimentally detected data.

14 In this context, the way in which the subject interprets his emotional reactions and his consequent behaviors is relevant: and this depends on the image or schema of self, in which the development of a gender identity (male, female) and an identity of role is fundamental. These are the result of learning processes deriving from the organization of existential experiences; from the systems of beliefs or values in which, as far as sexuality is concerned, moral, aesthetic and sometimes even hygienic evaluations are involved, which are attributed to the sexual sphere in general (sex as sin or dirt, or sex as pleasure or responsibility) and to some specific sexual habits. There are also convictions about what should be the appropriate characteristics of those who occupy a given role (i.e. husband, wife, lover) and what others expect from him/her in certain situations (i.e. during a sexual relationship); and from the systems of knowledge and skills that represent the known or established (or presumed) facts in possession of the subject and of the various types of skills that he has learned during existence.

15 The inexistence, compromise or inadequacy of social skills, connected to low self-esteem and difficulty in showing empathy, seems to be one of the main characteristics of sexual aggressors (see also Palermo, Mastronardi, 2005, p. 212) 
tatives of the other sex, which causes uncertainty and anxiety towards the behavior of others.

The list could go on but, for our purposes, it counts to have enucleated a series of cases, useful primarily to grasp the intuitive relapse on violent sexual behavior: in most rapists, there is a strong state of tension that leads them to in action gestures felt as unjust but "necessary" to prevent the emergence of states of paranoid anxiety and anguish (Di Renzo, Oscari, 2007, p. 33).

It is also useful to consider the incidence of the fear, often collectively subdued, of the possible and direct correlation between pornography and the increase in acts of violence (Dèttore, 2001, p. 99).

First, it is useful to introduce a reflection on the semantics of the term pornographic ${ }^{16}$, to draw the line of demarcation with other adjoining terminologies (erotic, obscene), but very different in content: which also allows to assume an attitude of neutrality towards the topic, generally interpreted as an expression of disorder and dysfunctionality or condemned because of not well-identified ethical reasons.

As noted by West (2004), it is not enough to define pornography as any sexually explicit material (visual or literary), because the characteristics considered pornographic differ according to the cultures and contexts examined. Rather, it is important to distinguish between sexually explicit material conceived entirely or primarily to produce sexual excitement from the material that has a completely different objective, as in the case of artistic representations.

Ogien (2003), with a probably more speculative approach, tries to circumscribe the field of pornography by focusing on the quality that makes a certain pornographic content. To this end he identifies some criteria, the first three subjective and two objective ones, useful for the qualitative research of the "pornographic":

1. intention by the author responsible for pornographic images to sexually stimulate the consumer;

2. affective or cognitive reactions of the consumer who may have a positive response (sexual excitement, pleasure, attraction, etc.) but also negative (disapproval, disgust, irritation, etc.);

3. affective or cognitive reactions of the non-consumer (probably only negative);

4. stylistic features (for example, repeated penetration scenes, close-ups on the genitals, etc.);

5. "narrative" traits (i.e. dehumanization of characters) (Quattrini, 2015, p. 29).

And then, "pornography" and "obscene" differentiate for their semantic content: obscene is what seriously offends the sense of modesty, where modesty must be understood as the sense of reserve, shame and discomfort with words, allusions, acts behaviors concerning the sexual sphere. Therefore, if pornography is a representation of sexually explicit content, the obscene is a reaction (or one of the possible reactions) to sexually explicit acts that arouse (offend) the sense of modesty. And this clarification is particularly important because it cuts - through an evaluation criterion - from the sample of sociological research (on sexual violence) non-consumers. Furthermore, eroticism, which we have already defined, differs from pornography due to the total lack of imagination and creative thinking. Eroticism recalls sensuality, pornography, sexual excitement ${ }^{17}$.

It is therefore possible to free the term pornography from rigid definitions and, constituting a manifest and immediate expression of the externalized erotic-sexual characterization of pleasure, it could be defined, as mentioned by Quattrini (2015, p. 224), as an empty "container", tended to fill the vast set of human sexual fantasies, but also as a faithful mirror of these fantasies. Pornography influences and / or represents its own consumer, which in turn is greatly influenced by it.

An emblematic example is that of the famous Serial Killer Ted Bundy, strongly convinced of the relationship between his violent behavior and pornography. In fact, in his famous interview released a few hours before the execution of death with the electric chair, he states ${ }^{18}$ :

"It happened step by step, not all at once. When I was a boy of twelve or thirteen, I found a pornographic journal randomly in front of the house. From time to time, to the boys of the neighborhood, it happened to find pornographic magazines, with increasingly strong and explicit graphics, of a much more explicit type of what we could find in the grocery store near the house or even in the police magazines [...] The most dangerous types of pornography are those involving violence and acts of sexual violence, because the union of these two forces leads to really terrible actions to describe. In my experience, once you're used to pornography that associates sex with violence, you can not do without it and it becomes a kind of addiction like drugs. I was constantly looking for new materials, stronger, more explicit, with more detailed descriptions. As in an addiction you are always looking for something more stimulating that increases your excitement. Until you reach that point in which to look is not enough for you anymore and you start wondering how it would really make some of those images you've watched an infinite number of times ".

Also, he declares:

"I've been in prison for quite some time to be able to say that the many men I met and who committed violence and abuse all nourished, without exception, a passion for pornography [...]".

Surely, Bundy's statements appear to be an attempt to shift attention to external factors in order to take responsibility, well aware from the well-established research that it is not an automatic equation (exposure to pornography = sexually violent behavior), as if this were so, we would potentially be all victims and creators of sexually violent behavior. On the other hand we can not conceal what is upstream, from the sociopathic diathesis to the paranoid diathesis, to the frankly psychopathological brand issues. However, we must consider that the continuous observation of violent behavior reinforces the probability of carrying out violent behavior already present in the subject. It should not be forgotten that the continuous exposure to the same stimulus leads to desensitization and inurement, the most serious effects of addiction, for which the subject needs stimuli more and stronger over time. This scheme is typical of the serial killer ${ }^{19}$ (Howard et al., 1971, p. 97).

The hypothesis of direct correlation in key of direct proportion between pornography and rape (that is, acts of sexual violence)

16 The term "pornographic" comes from the Greek porne ("prostitute") and grafia ("written"): therefore, literally, "written or figurative representations of prostitutes". As is evident, the etymology of the word does not suggest its current use, since many of the representations commonly called "pornography", in the contemporary sense, do not concern prostitutes or prostitution. The only constant of commodification worthy of mention is the great business that lies behind the porn industry, but it is certainly out of place to talk about "prostitution".

17 Among other things, it is undeniable that eroticism, in its broadest sense, uses images of manifest sexual acts in the same way as pornography, and often, even with artistic intent, to arouse excitement.

18 See http://www.pureintimacy.org/f/fatal-addiction-ted-bundysfinal-interview/

19 Howard, J. L., Reifler, C. B., \& Liptzin, M. B. 1971. Effects of exposure to pornography. Technical Reports of the Commission on Obscenity and Pornography, 8, 97-132. 
can be useful to provide sociological foundations for a "model", or "cognitive scheme", able to explain the phenomenal implementation of abusive behavior ${ }^{20}$ and, ultimately, can serve to consider the validity of solid crime prevention mechanisms.

However, no study has established any definite relationship between the consumption of pornography and any lasting change in basic attitudes and sexual patterns of consumers. The same physical location of pornographic material in virtual places (Internet), by definition without filters and imprecisable usability, makes it pioneering the identification of a model from certain deterministic and scientifically valid perimeters. The dilatation of virtual pornographic space and the related enlargement of the consumer population provides a wide criminogenic matrix for deviant behavior, whose exploration can only happen through the reference to the single context of cognition of the fact (the risk would be a pulverized analysis of criminal phenomena on a planetary scale, with consequent effect of disorientation and approximation). Which should not discourage the heuristic exploration in examination: surely, the exposure of the female genital organs, focused as an instrument of pleasure for man, underlines the attribution of the feminine passivity to the "natural" relationship of man-woman dominance. In pornography some aspects of sexuality are accentuated, and many others are suppressed (tenderness, concern and in general the erotic gradient of sexual activity) with the effect of flattening the complexity of the phenomena exposed. It is concluded that pornography places women in subordinate roles for which sexual violence can be encouraged with a "trigger" effect for rape behavior.

The two most widespread explanations of the causal process that would link sexually explicit materials with rape, consist in the hypothesis that such publications would portray violence against women and show them as sexually subjugated objects.

Another theory is offered by the studies of Jaffee and Strauss (1987), and asserts that rape is a function of two series of social forces. The first of these, social disorganization, is reflected in the detection that a large percentage of variance is explained by poverty, urbanization and divorce. The second factor is an orientation towards gender and sexual roles that can be summarized in the concept of "hypermasculinity". The hypothesized causal sequence starts with a violent society dominated by males, which produces the form of hypermasculinity. Therefore, the greater the presence of this hypermasculinity module in a population, the greater is the reading of pornographic magazines and the rape rate. This model has the advantage of allowing the construction of generally preventive hypotheses: education and even political interventions should be aimed above all at modifying hypermasculinity attitudes, rather than merely prohibiting or reducing pornographic publications.

In this regard, especially in Anglo-Saxon contexts, the subject of porn-pedagogy was addressed, in order to remove taboos related to the argument that, distancing the pornographic material from the primordial desire for sexuality, ends up causing the drift towards the extremism of behaviors that have nothing to do with the pleasure and well-being of one's own body.

\section{Psychopathological connotations and psychodynamic profile of the sex offender}

In the broad context of paraphilias are included all those aberrations or sexual deviations generally associated with sexual fantasies. The complexity of the phenomenon of "sexual violence" is to be connected precisely to this contemporary presence of both aggressive and sexual aspects. The clinical framing of the sexual aggressor in a strictly psychopathological framework may not be automatic: in fact, in more or less serious psychopathological situations, the scientific literature also highlights the presence of factors more precisely related to psychosexual immaturity, inadequacy genital, infantilism, compensation for affective deficiencies etc.

Several studies confirm the hypothesis that a high percentage of sexual aggressors has suffered abuse during childhood, triggering the "repetitive cycle of abuse" or "transgenerational transmission of the abusive model", where the aggression carried out by the subject seems repeat the same aspects of victimization suffered by him in terms of the type of act performed. It is the conquest of scientific literature that one of the harmful effects of assisted violence (and therefore acted upon by parents or by persons cohabiting with the child or who constitute for them a behavioral model) is the raising of the tolerance or addiction threshold; in fact, repeatedly assisting in episodes of abuse tends, over time, to make them fit into the inner "norm" (Schimmenti, Capraro, 2014, p. 28). Furthermore, tracing the cause of family delinquency is an extremely complex operation, since it is not possible to separate criminality itself from this perspective and the reasons that lead to delinquent individuals within the social system in which they live (together with the family). As mentioned, in fact, several studies have shown how the violence suffered by their parents, during childhood and adolescence, can be subsequently reproduced against their children, when assuming the parental role. The repetitive cycle of abuse, an evolutionary factor of violence (Anceschi, 2008 , p. 230), in this sense, postulates a perpetuation of violence, that is: the experiences of deprivation and violence, suffered by parents, would sediment so deeply as to create a "continuous experience of negativity of reception", for which one receives "always the negative" and confers in the same parent an attitude of suspiciousness towards the external world ${ }^{21}$.

This psychodynamics escapes deterministic rules. Although the correlation between the type of the birth family and criminality is important, i.e. the correlation between parental behavior and the formation of stereotypical representations of the male and female gender, the non-mechanical relationship between family inadequacy and the non-sociality of children is immediately perceived from the simple observation that, in the same nucleus, some of the children can have an adequate behavior, and others, on the other hand, a delinquent behavior (Ponti, 1999, p. 460).

Some particularly interesting statistics, investigate the parenting influence in childhood on subjects who later became rapists ${ }^{22}$, revealing that the dominant parent figure in the house was:

a) $50 \%$ had been the mother;

b) $40 \%$ had been the father;

c) $10 \%$ some "other" adult person.

This seems to support the hypothesis that their anger against women (sometimes real misogyny) may have originated in an ambivalent relationship and unsuitable with the mother figure. In fact, the relationship with the mother had been declared "affectionate and close" by 36\%; "Variable" from 31\%; "Cold and distant" from $5 \%$; "Careless and indifferent" from $10 \%$; "Hostile and
20 Of which we will talk in depth below.

21 On the psychodynamic aspects of maltreatment, vds. Mastronardi, 2012 , p. 372 et seq... The author goes on to infer that "the same parents thus develop a weak and disharmonious immature-I, which does not allow them to bear physiologically, with valid compensatory capacities, penalizing situations, thus structuring the transfer of psychic tensions, on a behavioral and interpersonal plan" (cit., page 373).

22 This is the Hazelwood study, reported in Palermo, Mastronardi, 2005 , p. 209. 
aggressive" by $18 \%$. The father, instead, was seen "cold and distant" by $31 \%$; "Variable" from $26 \%$; "Affectionate and close" only by $36 \%$. In any case, the percentage of declared psychological and sexual abuse by these subjects ranged between $73 \%$ (mother) and $76 \%$ (father), thus supporting statistically - with all the prismatic limits normally inherent to the statistical data - the cited evolutionary factor of violence.

According to Lichtenberg (1992), there would appear to be three risk factors for the genesis of a violent personality ${ }^{23}$ :

a. Learning violence as an effective and fast response. Violence contains in itself a double message or a double identification with the victim and the executioner. If this type of culture is shown to subjects who are not yet able to operate on a rational basis, violence will turn into emotional agitation without being intellectualized by the Super-I;

b. The presence of a parental refusal: not only as abandonment, but also with lack of care (as well as hypercuria and dysuria) physical, mental and emotional during the growth, in particular, as mentioned, by the mother figure.

c. The presence of a disturbed sexuality: as previously mentioned, this imbalance leads to the development of disturbing fantasies as well as paraphilias and therefore the implementation of deviant behavior.

But let's go back to the criminological specificity of sex offenders. In this perimeter, beyond the situational factors (family) that certainly affect, and we have talked about, what scientific research has led to hypothesize is that the sexual aggressor, from a strictly clinical point of view, would have typical characteristics of some personality disorders and that the most significant deficit was related to empathic abilities. Specifically, they have been identified as recurrent personality disorders (Petruccelli, Pedata, 2008, p. 56):

a) the narcissistic personality disorder: typical elements of this disorder are the lack of empathy, feeling special compared to others and feeling their needs as special and more important than those of others, are elements that could motivate sexually deviant behavior. The need for excessive admiration can hide a strong insecurity and a low self-esteem that, to be won, are transformed into a prepotent and pretentious attitude. This anguish of "sexual comparison" is particularly common in subjects who turn their erotic attentions on minors;

b) the antisocial personality disorder: the typical diagnostic criteria of this disorder (including impulsivity, irritability, lack of remorse) seem to channel unequivocally on a crime-dynamic profile typical of rape, or those types of sexual abuse that use violence and compulsion in the implementation of behavior. Moreover, the specific criterion of lack of remorse seems to be at the basis not only of deviant action, but also of its recurrence.

c) the limited empathic abilities: difficulties or deficits related to empathic abilities refer to the quality of the relationship with parents, especially with the mother ${ }^{24}$; it seems that the inhibition of these capacities can derive from a dysfunctional development of the personality due to biological or social disadvantages that do not allow a differentiation of simple or complex emotions; or by a voluntary refusal to pay attention to the other's feelings. Besides constituting a factor generally functional to crime, in the specific area of sexual crimes it is evident that the lack of empathy involves a poor inhibition of aggressive sexual behavior, considered not harmful and in any case not a harbinger of the suffering of others. Males who attack women and / or children can consider victims as different from them and have difficulty taking their perspective: deficiencies in the replication of emotions involve difficulties in recognizing their emotions and the identification of the emotional state of the other is unlikely. The perversion in this area appears to us as eroticized hatred, the expression of an ambivalent relationship with the female maternal figure (Mastronardi, 2012, p. 325).

It follows that the lack of empathy is one of the main characteristics of sexual aggressors, for whom the victim is only a sexual object on which to exercise his own strength and violence. The relationship between low self-esteem and difficulty in showing empathy may be related to more general difficulties inherent in social skills, such as difficulties during social interactions. It can be hypothesized that sexual aggressors find it difficult to establish intimate relationships, and this leads them to look for experiences of closeness through sex, to the point of clumsily and violently forcing victims to have sexual relations. On the other hand, we have already spoken about the ontogenesis of sexual behavior and the influence that social skills exert on it, so that, as a corollary, it follows that the conception of sex, experienced as a compensatory experience of the reluctance of relational inadequacy in creating relationships of intimacy, generates in these subjects' states of anguish easily leading to violent acting-out. Sexual gratification is especially functional to appease states of anguish, in a psychodynamic view of "attachment and loss", and to a partial satisfaction of the need for intimacy.

On this basis it is possible to construct a psychodynamic sequencing of sexual aggression (Palermo, Mastronardi, 2005, p. 213), useful to grasp the intrinsic inner flow of the offender until the verification of the violent event and, consequently, obtain a predictive mantra of its behavioral options, supporting hypotheses of reiteration (seriality) and predisposing useful prevention mechanisms (treatment).

\section{Psychophysical and relational status of normality}

\section{$\downarrow$}

Intrusion by elements of one's own background (e.g.: unresolved infantile traumas, perceiving oneself as victim of others, feeling inadequate, attributing one's suffering to others, etc.)

$\downarrow$

The dissatisfaction caused by these intrusions causes the subject to feel entitled to satisfy his retaliation desires.

$\downarrow$

A state of cognitive simplification is created, in which he begins to diminish the negative considerations related to a possible aggression.

$\downarrow$

Focusing more and more on his personal desires, he begins to behave in a way that is closer and closer to aggression: for example, he elaborates deviant fantasies.

$\downarrow$

Cognitive distortion focuses increasingly on the victim: adult or child, deserves to suffer violence. From this point the concrete actions that characterize the aggression start.

$\downarrow$

The attacker makes contact with the victim.

$\downarrow$

Sexual aggression acts.

$\downarrow$

It frees itself from any thoughts or feelings of guilt following aggression, by means of rationalization or denial of the deed.

23 Lichtenberg F., Self and motivational system. Rutledge, 1992, p. 34.

24 Of which we have already spoken 


\section{Marshall protocol and treatment on empathy}

The emphasis on poor empathic skills - grafted onto the abusive model of cognitive distortions - provides the ideational basis for the repetitive cycle of the abuse protocol by Marshall, Anderson and Fernandez (1999) ${ }^{25}$. The Authors describe empathy as a process that develops in 4 phases: 1) emotional recognition; 2) understanding the perspective of others; 3) the experience of a shared emotional response; 4) the implementation of actions aimed at giving comfort or reducing suffering. The work with the sex offender regards the possibility of making the patients' emotions be identified, avoiding that the denial of damage caused other than oneself prevents the development of the empathic process. Synthetically, the intervention module on empathy is structured as follows:

a) increase the capacity of the sex offender to recognize emotional states, for example by telling the group an emotionally distressing event from the past and identifying at the end of the story the emotions that were experienced during the exhibition;

b) allow the group to identify the possible damages caused to the victims of sexual abuse. The example is to ask in turn to specify at least three or more consequences in which victims may incur a reference to aggression;

c) once the alleged damage inflicted on the victim has been identified and described, each offender must "attempt" to describe the deviant act suffered from the victim's point of view. In this phase, role playing, simulations and anything else useful for the dynamics of emotional activation are possible;

d) finally, after having experienced the victim victim-executioner emotions in a group, each offender is provided with the real report of the victim. Each attacker, after reading the reports, describes the victim's emotions and emotional reactions. The descriptions will be critically discussed within the group by the same offender.

As the authors point out, the intervention protocol seems to change the cognitive aspect of empathy and not the emotional one.

\section{Types of sex offenders}

Considering the above, it is evident that the uncritical overlapping of the psychopathological categories described with the heterogeneous phenomenological characterization of sexual violence risks being inaccurate, if not strongly approximate and, unsuitable to frame the phenomenon in its criminological complexity. This is because the research of the enteropathogenesis of violent sexual behavior requires a multifactorial approach towards the author: an attempt was made to give an exhaustive picture in the previous pages. So, it would be reductive and erroneous to ascribe to general diagnostic categories the hypothesis of criminal epiphany that, on the contrary, require the specific understanding of some behavioral patterns, that is the analysis of some symptomatic indices of the violator's personality (latu sensu) referring to the predilection victim of crime or the organization of criminal action. The equation between individuals with sadistic sexual behavior with the sex offender is incorrect, rather they incorporate a varied range of individuals with violent sexual behavior. To obtain an exhaustive overview on the author of sexual violence, we will carry out a Copernican revolution of the research method undertaken so far, shifting the focus from the causes that lead to the action that, depending on the protean verification, allows the sex offenders to be placed in a "phenomenological" taxonomy, to be subdivided into 5 types (Quattrini, 2015, p. 123), to which specific criminal factors are associated:

\section{Rapist}

Wanting to outline the typical details of the rapist, summarizing the results of different research (Palermo, Mastronardi, 2005, p. 1013, Petruccelli, Pedata, 2008, p. 37; Russo, 2010, p. 57), it is possible to identify four categories ${ }^{26}$ :

a) aggressive exploiters rapists, in which the antisocial component of the personality emerges with clarity, understood not only as a weak empathic capacity, but also as an easy proclivity to criminal acting out, due to irritability / aggression and low IQ, which does not allow to support the erotic opportunism of the moment (hence the allotropic definition of opportunist rapists). For this reason, they are also called "sex snatchers", rape being like an impulsive and predatory act of the moment. Some authors ${ }^{27}$ further subdivide this category into: Type 1 aggressors, with considerable relational possibility (social competence) with the beginning of the criminal career in adulthood; and Type 2 aggressors with poor social skills and beginning in adolescence. Moreover, the predatory rape, that is a sudden aggression by a stranger, is the one most likely to be reported to the police ${ }^{28}$. The predatory rape argument is also interesting on a diagnostic profile, and that leads directly to a Paraphilic Disorder belonging to the type of disorders with another specification: the biastiofilia, from the Greek "biastes" (aggressor, violent) and "philia", then "violent love ". This Paraphilic Disorder concerns the attraction and excitement of sexually engaging an unknown person. Sexual contact is unexpected and physically violent. Usually the term is used to describe violent individuals and serial rapists. Usually, biastiophilia overlaps with herophonophilia (desire to kill). There does not seem to be any difference between man and woman, nor between homosexuals and heterosexuals. The condition in which excitement begins on the response of the act of violence is described by the term "raptophilia". According to the study of Money (1990), several factors seem to contribute to the formation of a personality with a biastophilic focus: a) genetic predisposition; b) hormone imbalances under development; c) relational problems (family), as possible sexual abuse; d) psychiatric syndromes (Quattrini, 2015, p. 208).

b) reassuring compensators rapists. The sexual immaturity of sex offenders belonging to the category is reflected in the low selfesteem and the sense of inadequacy that pervades them: precisely their characteristic behavior expresses reassuring power

25 Treated and "eviscerated" analytically by QUATTRINI, 2015, p. 133.

26 We must consider the non-overlap of sadistic violence and sexual violence latu sensu examined. In general, studies conducted on samples of sex offenders (rapists) and sexual sadists show clear behavioral differences. The rapists do not seem to be closely related to sexual sadists (5-10\%). In sexual violence, aggression has a prevalent interest in a victim, which must be resistant and not consenting, but not necessarily suffering. In sexual sadism, sexual erotic excitement is mainly directed at procuring physical suffering and / or mortification of the chosen victims. Sexual sadists are characterized by excitement through gratuitous violence, while rapists employ their strength according to their own needs, to gain subtly the complicity of the victims.

Individuals recognizable with a certain sadistic violence differ from sexual sadists in the object of sexual arousal during their prevaricating action (Quattrini, 2015, p.122).

27 Knight (1999), reported in Palermo, Mastronardi, 2005, p. 219.

28 On the contrary, it is Jordan (2008, p 57) who, about rape by a stranger, states that "[...] this type of rape is one of the least reported sex crimes and the most difficult to investigate; moreover, investigations rarely lead to a positive outcome". 
over the victim (for which some Authors call them "gentleman rapists"). They are usually lonely with fantasies about their victims and enjoy the experience inflicted upon them, and they can even develop loving feelings towards them. Typical paraphilic disorders in this case are voyeurism, fetishism, exhibitionism and disguise. In this typology the "non-criminal nonsadistic sexual" flows, since this type of abuser compensates his sexual inadequacy with the submission of the victim, without giving her any possibility of rebelling;

c) rabies-vindictive rapists or displaced anger: characterized by permanent disinhibition in the implementation of sexual abuse, because anger and hostility do not allow socio-affective feelings. The vindictive rage is intrapsychic and of very ancient date: once again the maternal ancestral role re-emerges and, especially in conditions of conflict (in the violence between partners, VP Intimate Violence Partner), rape becomes an instrument to confront the persecutory maternal phantom and reaffirm the its own repressive power through physical and psychological annihilation, intimidation and submission of the victim (Schimmenti, Capraro, 2014, p. 162). The interesting fact is that in these subjects emerges a level of sexual excitement of the same entity, both during the viewing of scenes of sexual violence, and during the viewing of scenes of consenting sexual activities. Hardly, this type of rapist proves a real sexual pleasure in doing the abuse, thus relegating the victim to be a simple "scapegoat", often representing a person or group that the attacker hates (and for this reason, rabies is not erotized exclusively towards women and aims directly at the denigration / humiliation of the other);

d) sadistic rapist ${ }^{29}$ : in this case sexuality is connected to the aggressive act, the more violent the more excited. The rapists who belong to this category, with clear antisocial behavior often characterized by psychopathic personality, vent their sadism to extreme consequences, very often killing the victim. This type usually includes serial killers with a sexual background. The latent sadist is distinguished from the sadistic overt, who is characterized by the same aspects of the first, but without feeling the need to brutalize his victim. Finally, nonsadistic rapists (muted) are mostly attackers with a profound sense of virile inadequacy ${ }^{30}$.

\section{Child molester}

They constitute a heterogeneous category of the population (men, women, homosexuals, bisexuals). An important feature is the use of subtle manipulation of the victim, with persuasive behavior of verbal type and / or physical coercion, emotional manipulation, seduction, flattery, gifts.

This aspect is very similar to the behavior also used in Pedophile Disorder.

For the purposes of a suitable classification, it appears useful to follow the scheme currently accepted by the US, F.B.I. ${ }^{31}$, which differentiates (also Russo, 2010, p. 64):

a) Situational child molester. They are individuals who occasionally commit acts of violence and abuse against minors. Preference is not exclusively for children. Even the most vulnerable individuals, such as the elderly, the disabled and people with serious mental illness, are the target of their attention. They are further differentiated on the basis of personality characteristics regressed (where there is a poor ability to adapt social and interpersonal), morally indiscriminate (which makes no difference between children and adults, using the minor for personal sexual interests), sexually indiscriminate ( in which the child sexual abuse input seems to be boredom and monotony, in these subjects there are generally parafilical fantasies and associated para- philic disorders are not excluded), inadequate (insecure subject often described as socially marginalized individual and with possible associations of other disorders, such as psychosis, personality disorders, mental retardation ...);

b) Preferential child molester. This type includes offenders who have a clear preference for minors. Their psychophysical condition is less conditioned by external stressors, either social or relational. The use of pornography is connoting, with attention to collecting pedopornographic material. In this context, the types of seductive are declined (an individual who, through courtship and seduction, aims to gain the full trust of the child), the fixed (offender with poor psychosexual development that lures young and unknown children using a minimal and often child-like verbal communication) and the sadistic (with characteristics already known, oriented on victims chosen randomly and outside the circle of minors known to him).

In summary, to have a comprehensive overview of the type of offender examined, it appears useful to propose the tables prepared by the US F.B.I. (Tables 1 and 2).

\section{Female sex offender}

"If the sexually aggressive individuals would gather together in a great infernal Dantesque circle, the overwhelming majority would be men" (Bourke, 2011, p. 239). This is true according to the judicial statistics (strongly infectious by the "gray number" of crimes that are not registered / perceived in general for what regards violence caused by the male, considered in the case of the woman raping ${ }^{32}$ ) and above all according to the collective social imaginary and cultural, despite the legal definition of "sexual violence" is distinguished from the concept of fellatio and, in general, equates the aggression to the sexual sphere depriving it of any reference to penetration of the penis: which confirms, even on the criminal level, the possibility that the woman is capable of sexually abusing, not just of a minor in the case of Pedophile Disorder. What emerges from the specialist literature on this phenomenon is that generally they are women who are in problematic conditions determined by the use or abuse of alcohol and drugs, with mental problems, reduced social skills, or with IQ reduction.

In this regard, in 2007 the U.S. Department of Justice has attempted to identify a number of risk factors for sex offenders, identifying the following:

a. stories of mistreatment and abuse, including sexual, during childhood;

29 Also called sexual rapists, where the addition of the term "sexual" to the definition "rapist", which already exists if it refers to a bloody sexual act, wants to focus specifically on sexual activities. Briefly: in sexual violence, aggression has a prevalent interest in a type of victim, which must be resistant and not consenting, but not necessarily suffering. In sexual sadism, erotic-sexual excitement is mainly aimed at providing psychic suffering and / or mortification in the chosen victims. Sexual sadists are characterized by excitement through gratuitous violence, while rapists employ their strength according to their own needs, to gain subtly the complicity of the victims (Quattrini, 2015, p. 122).

30 On the difference between sadistic violence and rape, non-overlapping concepts, we have already spoken before (par. d, about Paraphilic Disorders).

31 Cfr., https://www.ncjrs.gov/pdffiles1/Digitization/149252NCJRS.pdf.

32 Furthermore, we must consider that women who harass men or other women are usually accused of obscene or immoral conduct rather than carnal violence, and this confuses the statistical comparison between the crimes committed by males and females. 
b. symptoms of mental disorders, personality disorders, substance abuse problems;

c. difficulty in intimate relationships or absence of relationships;

d. tendency to victimize children and adolescents (rarely adults);

e. tendency to commit crime against a person with whom they have a connection or otherwise well known;

f. a growing likelihood of committing abuse with a partner.

These are characteristics that in any case do not share all the women interviewed / judicial investigations and, the data should be read looking, on one hand, the possible review for the trial purposes of the historical fact or a good faith production of false memories (with regard to the remote abuses suffered) and, on the other hand, the tendency to overestimate the incidence of psychopathologies due to the clinical sample from which these data are evinced and from the social alarm that such actions arouse $\mathrm{e}^{33}$.

In most cases, violence is perpetrated on child victims, both in the family and non-family environment, with complete aggression; the cases of aggression by women over male victims are rare, and the data show that this type of aggression is carried out by two or more women on a single victim, or by a woman with the complicity of a man (so-called co-offender), with a complete sexual relationship (Palermo, Mastronardi, 2005, p. 216). Especially in the domestic / family environment, it has been found that the possible variations of female sexual violence can involve passive or active attitudes, where "passive" (or indirect) sex offenders refer to those women who observe the abuse in progress and do not intervene adequately to stop it, or allowing children to observe adult sexual activity 34 ; while sex offenders "active", or direct, means those women who participate directly in the abuse, involving the victims in various sexual acts. The latter can carry out a wide variety of sexual behaviors, starting from seductive behavior, exhibitionism, caresses to the genitals of minors, to invasive acts of penetration (also using external objects), abuse during rituals or group abuse. Other frequent behaviors may not include physical contact (e.g. obscene phone calls, voyeuristic attitudes, exhibitionism), such as induction to prostitution or pedo-pornography.

Matthews, Matthews and Speltz (1989) ${ }^{35}$, among others, identify three types of female sex offender:

a) teacher / lover: offender women who have an interest in manipulating young adolescent males to educate them to adult sexuality and then start a love affair with them. Significant cognitive distortions are found that tend to justify and minimize the possible damage inflicted to these young people. Offenders tend not to consider their sexual actions as abuse. In order to carry on their need for excitement and sexual-erotic satisfaction with young adolescents, they shield the typically heterosexist idea of the young adolescent driven to have the first intimate-sexual relationships with an adult woman, thus resorting to strategies of moral disengagement or minimization of damage;

b) male forced / accompanied male: they are offenders that have a low self-esteem and seem particularly influenced by male partners dependent on substances. Often, they also abuse drugs and / or alcohol. Moreover, they live in an abusive relationship in which the partner forces them to carry out constricting and / or delinquent behaviors;

c) predisposed: usually it is a woman who has a history of sexual and physical abuse behind her. They generally act alone, and tend to victimize their children or other children within their family. Because of previous sexually negative experiences, the victim woman seems to be "predisposed" to enact a liberating abusive response, often to her own children. Deviant and / or violent erotic-sexual fantasies are present; usually the subject is looking for a power and control. We can suppose the existence of a cyclical process of violence, according to which the predisposition to commit violence is linked to a personal experience of violence suffered as a victim, during childhood or adolescence ${ }^{36}$.

33 Cf. Caso L., Da Ros T., Matano C., Women responsible for sexual abuse: a critical review of literature, in the Italian Review of Criminology - 1/2011, p. 39 and ss. (also obtainable from http://ojs.pensamultimedia.it/ index.php/ric/article/viewFile/612/592)

34 For example, not denouncing it to the Authorities.

35 Mathews R., Mathews J. K., Speltz K., Female Sexual Offenders: An Exploratory Study, Orwell, VT, Safer Society Press, 1989. See also Quattrini, 2015, p. 126; Palermo, Mastronardi, 2005, p. 217.

36 The "repetitive cycle of abuse" or "transgenerational transmission of the abusive model" has already been discussed above.

Table 1. Situational Child Molester.

\begin{tabular}{lllll} 
& Regressed & Morally Indiscrimate & Sexually Indiscriminate & Inadequate \\
Basic characteristics & Poor coping skills & User of people & Sexual experimentation & Social misfit \\
Motivation & Substitution & Why not? & Boredom & Insecurity and coriosity \\
\hline Victim criteria & Availability & Vulnerability and opportunity & New and different & Non-threatening \\
Method of operation & Coercion & Lure, force, or manipulation & Involve in existing acivity & Exploits size, advantage \\
\hline Pornography collection & Possible & Sadomasochistic; detective magazines & Highly likely; varied nature & Likely \\
\hline
\end{tabular}

Table 2. Preferential Child Molester.

Seduction

Sexual preference for children

Collects child pornography or erotica

$\begin{array}{ll}\text { Common characteristics } & \text { Sexual preference for children } \\ \text { Collects child pornography or erotica }\end{array}$

Motivation Identification

Victim criteria Age and gender preferences

Method of operation Seduction process
Introverted Sadistic

\begin{tabular}{ll} 
Fear of communication & Need to inflict pain \\
\hline Strangers or very young & Age and gender preferences \\
Non-verbal sexual contact & Lure or force
\end{tabular}




\section{Teenagers sex offender}

They are sex offender, generally male and with a previous history of delinquent type. The average age is 14 , with the peak of boys aged 15 and girls 13 . Teen sex offenders have difficulty controlling their own impulses and Learning and Schooling Disorders. Mental illnesses are often present (Quattrini, 2015, p. 127).

Among the attempts at classification, the model proposed by O'Brien and Bera (1986), called PHASE Typology, which founds the distinction between JSOs based on sexual abuse, is particularly interesting. This model identifies ${ }^{37,38}$ :

a. naive experimenters ${ }^{39}$;

b. harassers of under-socialized children ${ }^{40}$;

c. harassers of pseudo-socialized children ${ }^{41}$;

d. sexually aggressive abusers ${ }^{42}$;

e. sexually compulsive abusers ${ }^{43}$;

f. impulsive disturbed abusers ${ }^{44}$;

g. abuser influenced by the group ${ }^{45}$.

\section{Cyber-sex offender}

With the expression computer crime we want to refer to two types of crimes: the first defined crime by means of the computer and the second crime that exploits the use of the computer (Ponti, 1999 , p. 391). In this sense, sexual perversion finds plausible vent in both definitions, tracing - with the gradual evolution of computer technology - a parallel evolution of the phenomenology of sexual deviance.

In general, there are three "telematics" crimes associated with sexual abuse: a) downloading child pornography material making it accessible to others via the Internet; b) to send pornographic images to minors; c) to attract or solicit sexual erotic expressions in minors through the Internet (Quattrini, 2015, p. 127). Following the taxonomy described by McLaughlin (1998), four types of cyber-sex offenders can be framed:
a) collectors $^{46}$;
b) travelers $^{47}$;
c) producers 47 ;
d) chatter $^{49}$.

\section{Investigative and victimological approach to sex crime}

\section{Semeiotics of sexual violence}

To achieve an effective investigative approach to sexual violence, the victim's body must be considered to be the crime scene. In this way, by assimilating criminalistic tools to specialist health facilities $^{50}$, aimed at the relief and survey (like the 354 of the Italian Penal Code) or the prospective reading of criminodynamics, sufficient caution and sensitivity will be given to evaluate the individual clues and - in the light of what has been described in previous chapters - rise to a unitary logic, capable of triggering a useful inferential logic aimed at the historical-legal assessment of the fact and identification of the author (or at least of a valid profiling). The investigative approach, however, can not ignore the victimological regard to the injured person, considering both the brutality of the aggression suffered, and because the reconstruction of the narrative of the investigated facts is undermined, ab initio, by removal mechanisms, which it is necessary not only to stop but to manage with empathy and through specific therapeutic treatments.

For this reason the zetetic gradient of the "semeiotics of sexual violence" should not be overlooked, id est the "relief of signs", bearing in mind that the "signs" are not always visible, and the vis- ible signs are not always the most significant. It is important to grasp carefully and sensibly those that the violence leaves in the body, but also the whole series of other aspects, behaviors, emotional reactions that need to be decoded (Di Renzo, Oscari, 2007,

37 O’brien M., Bera W.W., Adolescent sex offenders: A descriptive typology, in Prevention of SexualAbuse, 1 (3), 1-4.

38 See Serena C. (2015), Juvenile sex offenders: typology, recurrence and treatment, in Psychology \& Justice, Year XVI, 1, (from the website www.psicologiagiuridica.com/pub/docs/JUVENILE\%20SEX\%20OFFENDERS.pdf)

39 These are young teenagers between 11-14 years. It is the situation that determines abusive behaviour, the victim is often very young between 2-6 years, the primary motivation of the abuse is to explore and experience the newly discovered sexual sensations. Sexual acts are mostly naive, nonrecurrent.

40 These are socially isolated individuals, not accepted by the peer group, attracted to those children who receive admiration. They often manipulate the victim and sexual acts are aimed at achieving intimacy, satisfying the need for self-importance, self-confidence or independence.

41 These are individuals who have often experienced sexual, physical or psychological abuse and who apparently seem to show adaptive behaviour and have adequate coping strategies. Their abusive behaviour is highly rationalized and in most cases they do not show signs of remorse or guilt. Abuse is described by them as a mutually shared, intimate and non-coercive act.

42 These are generally impulsive adolescents, with a life history characterized by a strongly dysfunctional family. Abuse often resorts to coercion and threat of violence and is aimed at achieving a sense of personal power or release from a state of tension, anger or frustration.

43 These are individuals who present traits of sex addiction, therefore a real obsession with sex. Often these are abuses that are hands off, so do not include physical contact, such as exhibitionism, fetishism, obscene phone calls or voyeurism, to become an experience of relief and elevation of the spirit.

44 The background of these subjects is characterized by serious family problems, experiences of substance abuse or intellectual disability. Sexual abuse is characterized by impulsivity or it could be the expression of a perception of disturbed reality.

45 They are individuals who act in a group (herd) and the victim is in most cases known. Generally, the abuser attributes the blame to the victim or to the other members of the group. Often there is an abusive dynamic directed by a leader. The reason is to attract peers' attention, gain their approval, protect their reputation and win the group's leadership

46 They tend to possess a large amount of child pornography material, they are attracted by the peculiar physical characteristics of minors (age, sex, hair colour, etc.). These offenders are often single and do not have a social life, tend to isolation. As for Pedophile Disorder, they find themselves choosing a job that involves them directly with the minors.

47 Often just because of the choice of work, which forces them to move a lot, use the web and chat to meet individuals, usually teenagers. They engage victims by offering them gifts, for example journeys in which they can meet. They can collect pornography; however, pornographic material is used repeatedly and in a coercive manner.

48 Presents both, typical traits of the collector, since they tend to accumulate pornographic and pedopornographic material (and it would seem also erotic childish material), both peculiar features of the typology in question, since they are often directly involved in the production and publication of erotic images of childhood on the Internet. Many producers are sexually involved with minors and have a history of sex offender stories

49 They are usually present online and try to bring victims closer to the internet, proposing virtual meetings such as cyber-sex. They are persuasive and can easily get the victim's trust. Often the transition from virtual to real is preceded by telephone contact.

50 First of all, we want to refer to the sampling using: 1) pads for genetic typing: according to the story, biological traces of the aggressor can be searched on the skin or under the victim's fingernails, as well as any pubic hairs of the aggressor with comb new to medium-spaced teeth; 2) toxicological examinations that, based on the medical history, can be performed on blood or urine; 3) vaginal and / or cervical swabs for the research of: neisseria gonorrhea, vaginal trichomonas, chlamydia trachomatis, bacterial vaginosis. 
p. 98). The problem of the visibility of the signs is important, and the preliminary hint on the "phenomenology of violence" returns to intersect with the argumentative jokes that now come out: the (cultural) investigative error is the simplistic and approximate consideration of the equation between "semeiotics" of sexual violence and "cosmesis" of sexual violence, and that is to base the credibility of sexual assault on what can be read on the body and in the physical of the victim. This is wrong for several reasons, some even intuitive, and mainly because the most authoritative statistics show that, if we refer to sexually active adult women, in $90 \%$ of cases it is not possible to find any genital sign of the violence, while extragenital lesions are associated with a percentage lower than 20\% (Di Renzo, Oscari, 2007, p. 98).

From which it follows that the problem of semeiotics is not to judge the veracity of the story of violence, but to avoid leaving out important elements of analysis.

Having established this fundamental premise of method, we move on to consider the role of health workers, identified as the central figure in addressing the phenomenon of sexual violence by the guidelines of W.H.O. $(2002)^{51}$. The tasks that health professionals must be able to face are three: knowledge of the phenomenon and the ability to recognize it, welcoming the victims with appropriate professionalism; competence in offering the necessary medical treatment for immediate health problems and for the prevention of future pathologies; knowledge of the correct methods for collecting and preserving the finds and all that can be useful in case of legal proceedings. It is clear that this is a position of extreme delicacy, the effect of which can also be deleterious, or boomerang, in the sense of leading to the removal of the victim from health violence, unable to accept or to perceive the drama. It should not be forgotten that the mistrust towards institutions (health, police or justice) is indicated, for example in the ISTAT survey, as one of the main obstacles to the request for help (fear of being judged, treated poorly or with little confidentiality in $28.6 \%$ of cases, fear of not being believed in $22 \%$ ). Only $7 \%$ of women who have suffered violence report the fact to social, health and legal authorities. The statistics give voice in terms of data and numbers to that which has risen to an academic canon, whose label is "secondary victimization" 52 .

So the ability to prepare an empathic reception is essential: if not addressed and re-elaborated, violence can become an even more complex problem, with serious repercussions on the future life of the victim. It is desirable to offer psychological support to help deal with the consequences of violence, even over time. Making explicit a clinical frame of reference is useful to give the victim the elements in which he can recognize himself and understand the need to face events, without continuing to put in place mechanisms of repression. It may also be important to support the victim's family members, to help contain the emotions or anger that the event inevitably arouses. Within a therapeutic relationship, women can be helped to reprocess images (flashbacks) that recur in an intrusive and unpredictable way, to reread the nightmares that torment sleep, to restructure the erroneous convictions matured after violence, to confront problematic aspects of everyday life. The aim is to promote the possibility of regaining possession of one's own life that violence has interrupted or compromised and of re-establishing one's own "self" (Di Renzo, Oscari, 2007, p. 98) ${ }^{53}$.

The experience of services that welcome victims of violence suggests the presence of a female figure. Moreover, the complexity of the traumatic event "sexual violence" and its consequences, require that the health worker does not intervene alone, but can make use of the collaboration of a colleague. Even health workers, especially if they work in an emergency, may be exposed to the risk of vicarious trauma, i.e. experiencing the trauma not by direct exposure but by contact with the victim. Sharing with a colleague or another operator can be an important resource.

In such a context it is easier than the "invisible semeiotics", wanting to use an oxymoron to synthesize the arguments, leaps to the evidence, acquiring greater body signs that however must be detected for an effective work of analysis, namely: the patient's attitude, his mental state, the amnesia and inconsistencies, the use of alcohol and drugs.

As for the examination of the body tout court it is worth pointing out that the same must proceed from head to toe, not neglecting areas sometimes neglected like the armpits, the back of the ears, the soles of the feet ${ }^{54}$. Furthermore, if the alleged assault is reported as having just occurred, it would be advisable to ask the victim for the material under the nails (Jordan, 2008, p. 81). The lesions must be documented in the best possible way, possibly through photographs, and accurately described with regard to the place, the dimensions and the shape, the depth, possibly the time elapsed from the lesion to the observation.

The genital examination is very often in vain, but it is absolutely necessary for the possible judicial process and also serves for the collection of tampons and vaginal material that may contain the DNA of the assailant. The most frequently observed lesions in the case of an undesirable sexual intercourse are detected at the level of the posterior commissure of the fork, in the labia minora, in the labia majora, at the imaltery or anal level: non-specific lesions can be observed (bites, cigarette burns, bruises), or redness, up to real lacerations.

The greatest difficulty in giving probative value to these findings is the fact that we do not know which types of microtrauma can be detected in a consenting relationship: therefore we can have lesions in a desired relationship and perhaps vice versa, a forced relationship without visible signs.

51 World Health Organization (1997), Violence, Against Women, Women's Health and Development Program, W.H.O., Geneva.

52 It is possible to speak of "secondary victimization" when the state apparatus that has to take charge of violence is not able to cope with the complexity of the phenomenon, reducing the review of the aggression to the minimum probation and emotionally soothing the trauma immediately (primary victimization). More specifically: the process of causing physical, mental, emotional or economic harm to the victim through the commission of a crime or exposure to threats is called "primary victimization". "Secondary victimization" can be defined as a condition of further suffering experienced by the victim in relation to an attitude of insufficient attention or insensitivity on the part of the formal control agencies (police, health, social and judicial systems) in the phase of their intervention and manifests itself in the further negative psychological consequences. And the balance between the state needs of ascertaining the facts and those of "moral" protection of the victim is an important issue: the narrative progression of the testimony is often articulated through non-overlapping declarations, which evaluated with some parameters of judgment often used in the practice of assessing the reliability, could lead to a negative judicial evaluation.

53 The Authors punctually point out that: "[...] it is always good to remember that people asking for help need care and not fury (neither psychological nor therapeutic); do not worry, but deal with it. The vulnerability of the victims, their difficulties, often make it more difficult to foresee a shared project out of violence. However, it is not in the woman that the cause of the violent behaviours suffered must be sought, at most they must be taken into account as predisposing factors to which attention should be paid to a primary prevention operation "(ibid., Cit., P. 96).

54 The method indications are mainly drawn from Di Renzo, Oscari, 2007, pag. 100 and ss. 


\section{Self-inflicted injury and Munchausen syndrome}

Among the investigative options can not be rationally abandoned that of the simulation of rape / sexual violence: and indeed the repeatedly stigmatized probative lability of the crime in question leaves ample margins of doubt in the investigator who, far from a skeptical approach towards those who report sexual abuse, can and must consider the hypothesis of self-inflicted injuries and, in the most extreme cases, the existence of mental disorders of diagnostic relevance, with particular reference to the so-called Munchausen syndrome.

In brevis, it is a psychiatric disorder that provides a pattern of fake disturbances, self-inflicted wounds, and may also consist of injecting toxic substances into the body to cause disease. People suffering from Munchausen's syndrome enjoy raising others' attention through their own illnesses (Jordan, 2008, p. 88). This syndrome is believed to be connected with false claims of sexual victimization due to the exaggerated need for attention. It is also seen as a means of manipulating people, more frequently directed towards the medical profession, namely hospitals and doctors; however, a fraudulent claim of sexual victimization can be interpreted as a form of manipulation of law enforcement or, on a larger scale, of the entire criminal justice system. It is not clear whether self-inflicted wounds constitute the product of a psychological disorder, such as the syndrome in question, or the mere staging of sexual assault falsely reported for other reasons. In this sense, staging (or the intentional alteration of a crime or crime scene in an attempt to deploy investigators and frustrate the criminal justice process) can subtend a double order of motivations, linked, on one hand, to the original action for which staging was necessary (greed, vindictive rage, desire for attention, game playing, etc.) and, on the other hand, staging itself (self-preservation, embarrassment-shame) (Palermo, Mastronardi, 2005, p. 103). However, in suspected cases of Munchausen syndrome, the sex crimes investigator will probably discover a history of manipulative incidents in the background of the alleged victim. If such a story does not exist, it could be the first manifestation of the disorder, and it is highly probable that there will be others.

Moreover, in the case of sexual abuse of minors and the craving of attention could be satisfied by transferring the lesions from the adult (the parents, usually the mother) to the child's body, thus leading to integration of the Munchausen syndrome by proxy. This is one of the iatrogenic disorders of the doctor-parents relationship and, as an expression of a particular maternal emotional neglect, it must be considered a form of violence on the part of the mother, who feels the need to consider her own child as ill, in order to attract attention on herself, feeling so erroneously, "particularly" and "really" useful and thus projecting on her son her own dissatisfaction and her deepest problems (Mastronardi, 2012, p. 368) ${ }^{55}$.

\section{Investigation (and judicial) approach: types of rape}

The distinction that is now proposed has the purpose of better dissecting from the strictly operative point of view, the possible ways of consummating sexual violence: it derives that the utility is pragmatic, useful for a primordial and immediate framing of the crime inside of investigative coordinates, whose continuation can lead to diversified scenarios.

The taxonomy, therefore, has an unscientific and indicative value for the inferential approach to the investigative thema by the justice operators (FF.OO. AG, lawyers ...), consists of five levels (Jordan, 2008, p. 57):

a) Sexual violence by a stranger. This type of rape implies the total estrangement between the victim and the aggressor, even if, once the sex offender has been identified, it could be discovered that in the past occasional contacts between him and the victim have occurred. The investigative typology in examination, it should be noted, is the operational reverberation of the already described aggressive rapist or exploitative opportunist 56 ;

b) Sexual violence occurred following an appointment. In this type of sexual violence between the victim and the assailant there is a social history, but generally no previous sexual relations. Although physical force is sometimes used in such situations, it could be limited to grasping, holding back, or pushing. Intimidation, verbal threats, fear and deception are the tactics most commonly used by the attacker. Generally, the victim has no injuries that can justify the alleged rape. As with sexual violence committed by a friend or relative, the relationship between victim and assailant changes dramatically as soon as the latter is in a position to take control over the former. From this moment on, the attacker presses the victim with the request for sexual acts or takes advantage of it after having induced her to make use of alcohol or drugs.

c) Sexual violence performed by a friend or relative. It would seem prima facie similar to the type described above: however, it should be noted that even if the victim and the attacker know each other, in the case of rape following an appointment, there may be very little or no interaction or social relationship between them. The attacker can be a family friend, a work colleague, a neighbor or a recent acquaintance. However, there are some similarities found in the behavior of the known rapist and in that of appointment: in both cases, the relationship between the two protagonist changes dramatically once the assailant is certain that he has acquired full control of the victim. The known rapist can be physically aggressive or use verbal intimidation to instill fear into the victim, so as to obtain his reluctant submission. It has been found that in this type of violence, the difficulty remains mainly probative in the judgment, in consideration of the absence of injuries (invisible semeiotics) due precisely to the state of vulnerability of the victim due to the intimidation of the offender.

d) Domestic sexual violence. We have already spoken of marital rape $^{57}$, with reference to sexual violence misunderstood with the idea of "fulfilling the conjugal obligations": but the concept is best argued in consideration of its phenomenological relevance, despite the recent investigative categorization, where more technically it is preferred split (due to the underlying criminological implications) between DVAW (Domestic Violence Against Women) and IPV (Intimate Partner Violence), which is the one operated by the partner, so that the physical space of consumption is not placed in the "domus" but in the intimate relationships between the subjects involved: if we look closely at the concept of IPV, including the characteristic of intimacy, the terminological option (of Anglo-Saxon derivation) appears to be more suitable to label the phenomenon (Baldry, 2014, p. 22). In any case, domestic violence is defined

55 The author goes on to describe a further variant of Munchausen's syndrome, "Medical shopping by proxy", involving children aged 6-7, visited by numerous doctors and hospitalized in several hospitals, in order to perform an impressive series of unjustified examinations, when, conversely, history and reported disturbances contrasted with the normal appearance and development of children. Of extreme interest it was noted that the same children were convinced that they were ill and confirmed the disorders reported by their mothers (ibi., P. 369).

56 Cfr. infra cap. 2.6 lett. $f$.

57 Vds. what was said in this regard under cap. 1.2. 
as "any form of physical, psychological or sexual violence that affects both the subjects they have, have had or are proposing to have an intimate relationship of couple, both subjects and within a family nucleus more or less extended have parental or emotional relationships ${ }^{58}$ ", based on cultural, economic, political and juridical factors.

e) Sexual misadventures. The "operative" expression coined by Jordan (2008, p. 68), although it may appear to be irrelevant towards those who suffer sexual violence, actually effectively describes two structural components of rape types: that is deceit and fraud used to sexually take advantage of the victim. In some respects, the author notes, the deception is more emotionally threatening and provokes greater anger in the victim, compared to the use of physical force and intimidation. Exemplifying: the victim is flattered for the sole purpose of obtaining a sexual performance, after which the offender's interest vanishes leaving only the sense of humiliation for the insult suffered. Although it is not overwhelming or constraining, this type of mechanism (especially in the emotional sphere) could cause the victim to shape the story of "violence", in order to protect self-esteem and self-image, inserting in the narrative the use of drugs or alcohol against him. Clearly, in these cases, the main difficulty is to diverge with circumstantial evidence of the exact dynamics of the event.

\section{Conclusions}

As in a Ringkomposition, I return to the conclusions to that initial fragment, since the conclusion does not deviate from the premise with regard to content but, at the end of a thematic path, it is strengthened by the composure and solidity of the arguments on which holds, now endorsed by a more critical reading also of the professional experiences of the writer.

So I venture to add that experience teaches that the investigative understanding of crimes related to violent sexual behavior requires, as primum movens, an "empathic approach" to the victim. This means that we start from the "victim" and that the key to accessing information assets in it must have "empathy".

In psychology for "empathy" 59 , we mean the ability to understand the state of mind and emotional situation of another person, in an immediate way and sometimes without resorting to verbal communication. The term is also used to indicate those phenomena of intimate participation and identification through which the aesthetic understanding would be realized (where aesthetics, in our context, is flanked by the "ocular" idea of beauty and approaches the semeiotic of violence treated previously). The exploration of the contents and of the empathic processes takes place for the first time in the field of phenomenology, constituting a decisive step to overcome a merely rational conception of interpersonal communication and, in particular, of the ability to understand the other (Treccani Encyclopedia, 1999).

So it must be considered that having carried out an analysis of violent sexual behavior, through the criminological and investigative vein, can have its own usefulness in the fact of being able to understand causes and effects of the same, giving a more eclectic and heterogeneous possibility of identification or empathy . For example, in the case of the investigator, in the victim of the crime: the empathic approach allows a greater awareness of all the communication channels (verbal, para-verbal and nonverbal) of the person, whether witness to the facts or offended person, ascribing them to general categories. The ability to understand the background of a complaint ${ }^{60}$, or to see the symptoms of a certain theo- retical model of abuse rather than another, in the exposition of the facts or in the info-investigative research, or to detect at the scene of the crime particular circumstantial characteristics, the result of non-peculiar psychodynamics, show that the purpose of the article is not (was) in itself heuristic, but operational.

In conclusion, while remaining the perversion and criminality (in their combinations) constant factors of human affairs, we want to emphasize the social role of education to a sexuality as much as possible oriented to mature emotional involvement, which can be an inhibitory factor to the commission of sexual crimes, and not only. We talked about hypermasculinity modules caused by excessive media exposure to pornography and porn-pedagogy: in the opinion of the writer, could also allow greater awareness of abused victims, as we have seen sometimes even unable to perceive the commission of the a crime brought to consummation against them, thus subrogating judicial and investigative inefficiencies that are risky little adequate to deal with delinquent dynamics and, in some cases, subtle and almost elusive.

\section{References}

ANCESCHI A. (2009), La violenza familiare. Aspetti penali, civili e criminologici, Giappichelli, Torino.

BALDRY A.C. (2014), Dai maltrattamenti all'omicidio - La valutazione del rischio di recidiva e dell'uxoricidio, V ed., Franco Angeli, Milano.

BARLETTA R., FEDERICI A., MURATORE M.G. (2008), La violenza contro le donne. Indagine multiscopo sulle famiglie "Sicurezza delle donne" anno 2006, Istat, Roma.

BOURKE J. (2011), Stupro - storia della violenza sessuale, Ed. Laterza, Bari.

CIAFARDINI L. et al. (2009), a cura di, Codice Penale Operativo - VI edizione, Ed. Giuridiche Simone.

DÈTTORE E. (2001), Psicologia e psicopatologia del comportamento sessuale, McGraw-Hill, Milano.

DI RENZO C.G., OSCARI G. (2007), La violenza sessuale, Aracne ed., Roma.

FERRACUTI F. (1987), Trattato di criminologia, Medicina Criminologica e Psichiatria Forense, vol. 8, Milano, Giuffrè

JORDAN F.D. (2008), Sex crime investigation - manuale completo dell'investigatore, Mediterranee ed., Roma.

58 Sic "Special Rapporteur on violence against Woman, its causes and consequences" of UNHRC - United Nations Human Rights Council.

59 The term derives its etymology from the ancient Greek $\dot{\varepsilon} v$, "in", and $-\pi \alpha \dot{\alpha} \theta \varepsilon 1 \alpha$, from the stem $\pi \alpha \theta$ - of the verb $\pi \alpha ́ \sigma \chi \omega$, "I suffer", on the cast of the German Einfühlung. Hence the idea that suffering is read in the shoes of the other, or rather it is possible to understand "in", "inside" the other-that-suffers, thus assuming that, initially, one of the two does not suffer and which, subsequently, deliberately drops an atmosphere of suffering completely alien, characterized by independent otherness.

60 On secondary victimization has already been discussed below, but in these considerations on empathy can not escape the relevance and consequences on the possibility of filing the gray number of complaints (which causes a superficial knowledge of the phenomenon in all its facets). As mentioned, sometimes the complaints (whose only narrative content could be very useful for understanding, reporting and inserting "in the system" the innumerable empirical variants of violent sexual deviance) not moved by lack of trust or even for the lack of "structural" ability of the police offices to appropriately accommodate the victim of a crime related to the sexual sphere. 
MASTRONARDI V. (2012), Manuale per operatori criminologici e psicopatologici forensi, Giuffrè ed., V ed., Milano.

PALERMO G.B., MASTRONARDI V. (2005), Il profilo criminologico - dalla scena del crimine ai profili socio-psicologici, Giuffrè ed., Milano.

PETRUCCELLI I., PEDATA L.T. (2008), L'autore di reati sessuali. Valutazione, trattamento e prevenzione della recidiva, Franco Angeli ed., Roma.
PONTI G. (1999), Compendio di criminologia, IV ed., R. Cortina ed., Milano.

QUATTRINI F. (2015), Parafilie e Devianze-psicologia e psicopatologia del comportamento sessuale atipico, Giunti ed., Milano.

RUSSO F. (2010), Lineamenti di psicologia criminale e investigativa, Celid, Torino.

SCHIMMENTI V., CAPARO G. (2014), a cura di, Violenza sulle donne, aspetti psicologici, psicopatologici e sociali, Franco Angeli ed., Milano.

\section{Correspondence: Monica Calderaro.}

E-mail: monica.calderaro@uniroma1.it

Key words: Criminology, sexual violence, sex offender, perversion, rape, sex crime investigation.

Parole chiave: Criminologia, violenza sessuale, sex offender, perversione, stupro, sex crime investigation.

Palabras clave: Criminología, violencia sexual, delincuentes sexuales, perversión, violación, investigación de delitos sexuales.

Received for publication: 12 July 2016.

Revision received: 21 October 2016.

Accepted for publication: 5 March 2017.

(C) Copyright M. Savastano et al., 2017

Licensee PAGEPress, Italy

Rivista di Psicopatologia Forense, Medicina Legale, Criminologia

2017; $22: 7-21$ 